Int. J. Electrochem. Sci., 15 (2020) 9459 - 9472

\title{
Measuring the Content of Unfrozen Water in Frozen Soil Based on Resistivity
}

\author{
Liyun Tang ${ }^{1}$, Xin Wang ${ }^{1, *}$, Fangyan Lan ${ }^{1}$, Peiyong Qiu ${ }^{2}$, Long Jin ${ }^{1,3}$ \\ ${ }^{1}$ School of Architecture and Civil Engineering, Xi'an University of Science and Technology, Xi'an, \\ Shanxi 710054, China \\ ${ }^{2}$ Department of Civil, Geological, and Mining Engineering, École Polytechnique de Montréal, \\ Research Institute on Mines and Environment (RIME) UQAT-Polytechnique, Montréal, QC H3C 3A7, \\ Canada \\ ${ }^{3}$ CCCC First Highway Consultants Co., Ltd, Xi' an Shanxi 710000, China \\ *E-mail: wangxindeli@163.com
}

doi: $10.20964 / 2020.09 .57$

Received: 10 May 2020 / Accepted: 3 July 2020 / Published: 10 August 2020

This study proposes a new method for calibrating the theoretical model of resistivity versus unfrozen water content in frozen soils. The method characterizes correlations between the soil mass resistivity and unfrozen water content in the frozen state by investigating the relation between resistivity and liquid water content in the drying state. The essential similarity between the soil mass freezing and drying processes is analyzed through the process and path of unfrozen (liquid) water reduction. The resistivity and unfrozen water (liquid water) content were correlated in soil samples with different particle sizes (clay, silt, and sandy soil) during freezing and drying. The test results showed that during freezing to temperatures below $5{ }^{\circ} \mathrm{C}$ (clay), $4{ }^{\circ} \mathrm{C}$ (silt), and $3{ }^{\circ} \mathrm{C}$ (sandy soil), the unfrozen water content thresholds of providing directional migration channels for conducting particles were $17 \%$, $14 \%$, and $13 \%$, respectively. During drying, the threshold water contents of clay, silt, and sandy soil were $15.35 \%, 14.87 \%$, and $14.34 \%$, respectively. The correlation between the soil resistivity $\left(\rho_{D}\right)$ and unfrozen water content $\left(\theta_{u}\right)$ in the freezing process can be expressed based on that between the soil resistivity and liquid water content in the drying state. Thus, the theoretical model of unfrozen water content can be calibrated by conducting a resistivity test under the drying condition. This new method is suitable for model calibrations of electrical resistance tomography for engineering applications in cold regions.

Keywords: Unfrozen water; Soil resistivity; NMR; Freezing; Drying

FULL TEXT 
(C) 2020 The Authors. Published by ESG (www.electrochemsci.org). This article is an open access article distributed under the terms and conditions of the Creative Commons Attribution license (http://creativecommons.org/licenses/by/4.0/). 